\title{
Comment on "Experimental reassessment of the Shaw paleointensity method using laboratory-induced thermal remanent magnetization" by Y. Pan, J. Shaw, R. Zhu, and M. J. Hill
}

\author{
Y. Yamamoto \\ Institute for Marine Resources and Environment, Geological Survey of Japan, National Institute of Advanced Industrial \\ Science and Technology, Tsukuba, Japan \\ Received 21 September 2002; revised 31 January 2003; accepted 3 March 2003; published 29 May 2003. \\ INDEX TERMS: 1521 Geomagnetism and Paleomagnetism: Paleointensity; 1540 Geomagnetism and \\ Paleomagnetism: Rock and mineral magnetism; 1594 Geomagnetism and Paleomagnetism: Instruments \\ and techniques; KEYWORDS: paleointensity, Shaw method, thermal remanent magnetization, anhysteretic \\ remanent magnetization
}

Citation: Yamamoto, Y., Comment on "Experimental reassessment of the Shaw paleointensity method using laboratory-induced thermal remanent magnetization" by Y. Pan, J. Shaw, R. Zhu, and M. J. Hill, J. Geophys. Res., 108(B5), 2278, doi:10.1029/2002JB002214, 2003.

[1] Pan et al. [2002] experimentally investigated the validity of the Shaw paleointensity method [Shaw, 1974; Kono, 1978; Rolph and Shaw, 1985] using laboratoryinduced thermal remanent magnetization (TRM) to simulate natural remanent magnetization (NRM). They prepared fully demagnetized Cretaceous basalt samples by exposing them to a $150-\mathrm{mT}$ alternating field (AF), and then heating them in an oven to $600^{\circ} \mathrm{C}$ for $20 \mathrm{~min}$ in a laboratory field of $50 \mu \mathrm{T}$ to produce the simulated NRM. The samples were then divided into three sets (A, B, and $\mathrm{C})$ and subjected to Shaw-type experiments. The TRM acquisition parameters differed among the sets: the 10 samples of set A were heated to $600^{\circ} \mathrm{C}$ for $20 \mathrm{~min}$ in a laboratory field of $50 \mu \mathrm{T}$, set B comprised 20 samples that were heated to $600^{\circ} \mathrm{C}$ for $30 \mathrm{~min}$ in a field of $30 \mu \mathrm{T}$, and 20 set $\mathrm{C}$ samples were heated to $700^{\circ} \mathrm{C}$ for $40 \mathrm{~min}$ in a field of $50 \mu \mathrm{T}$. After applying Rolph's correction [Rolph and Shaw, 1985], 29 out of the 30 samples in sets A and B yielded paleointensities close to the expected value $(50 \pm 5 \mu \mathrm{T})$, whereas only 9 out of the 20 samples in set $\mathrm{C}$ yielded values close to the expected. Since 8 out of the remaining 11 samples in set $\mathrm{C}$ showed incorrect intensities, Pan et al. [2002] concluded that monitoring rock magnetic properties such as the " $P$ value" (defined below) was very important when applying the Shaw method with Rolph's correction. Although in my view it would be better to further examine the validity of Rolph's correction by double heating [Tsunakawa and Shaw, 1994], study by Pan et al. [2002] is important to reassess the reliability of Shawtype experiments because of several recent criticisms [e.g., Goguitchaichvili et al., 1999; Vlag et al., 2000].

[2] However, because I do not consider the data processing used to construct the paleointensity plots of Pan et al. [2002] to be correct, different conclusions can be drawn

Copyright 2003 by the American Geophysical Union. 0148-0227/03/2002JB002214\$09.00 from their study. For example, sample $\mathrm{C} 20$ yielded a value of $62.6 \mu \mathrm{T}$ from the NRM-TRM* plot [Pan et al., 2002, Figure 2], which is $25 \%$ higher than the expected intensity. This plot showed excellent linearity in spite of the absence of linearity in the original NRM-TRM diagram. According to Pan et al. [2002], this linearity was produced by Rolph's correction. However, I do not consider the correction to be valid because the original NRM-TRM and $\mathrm{ARM}_{1}-\mathrm{ARM}_{2}$ plots (where ARM is anhysteretic remanent magnetization) had inverse convexity; in other words, they were dissimilar to each other. In Rolph's correction, linearity in an NRM$\mathrm{TRM}^{*}$ plot is generally produced by the resemblance between the NRM-TRM and $\mathrm{ARM}_{1}-\mathrm{ARM}_{2}$ plots (for example, sample B04 in set B [Pan et al., 2002, Figure 2]).

[3] This erroneous correction is probably the result of calculation without vector subtraction. In Rolph's correction method, individual TRM data for a certain coercivity are corrected by multiplying by the ratio of its equivalent anhysteretic remanent magnetizations (ARMs) given in the same field before and after the laboratory heating that produces the TRM. If the original and corrected TRMs for a certain coercivity $\mathrm{H}_{c}$ are defined as TRM $\left[\mathrm{H}_{c}\right]$ and $\mathrm{TRM}^{*}\left[\mathrm{H}_{\mathrm{c}}\right]$, and the ARMs before and after the heating as $\mathrm{ARM}_{1}\left[\mathrm{H}_{\mathrm{c}}\right]$ and $\mathrm{ARM}_{2}\left[\mathrm{H}_{\mathrm{c}}\right]$, then $\mathrm{TRM}^{*}\left[\mathrm{H}_{\mathrm{c}}\right]$ is calculated as follows:

$$
\operatorname{TRM}^{*}\left[\mathrm{H}_{\mathrm{c}}\right]=\mathrm{TRM}\left[\mathrm{H}_{\mathrm{c}}\right] \times \frac{\mathrm{ARM}_{1}\left[\mathrm{H}_{\mathrm{c}}\right]}{\mathrm{ARM}_{2}\left[\mathrm{H}_{\mathrm{c}}\right]}
$$

Then the linear portion of the NRM-TRM* plot is used to determine the paleointensity. In this calculation, note that each term on the right-hand side in equation (1) should be calculated by a vector subtraction between the measured and maximum AF steps $\left(\mathrm{H}_{\mathrm{c}}\right.$ and $\left.\mathrm{H}_{\max }\right)$. For instance, if the maximum $\mathrm{AF}$ step is $150 \mathrm{mT}, \mathrm{TRM}\left[\mathrm{H}_{\mathrm{c}}\right]$ is calculated by subtracting the TRM value measured after the $150-\mathrm{mT}$ AF cleaning from that measured after the cleaning of $\mathrm{H}=\mathrm{H}_{\mathrm{c}}$. 
This calculation is necessary because the maximum AF demagnetizing field does not necessarily erase all of the remanent magnetization, as stated by Rolph and Shaw [1985]. All the remanences $\left(\mathrm{NRM}\left[\mathrm{H}_{\mathrm{c}}\right], \mathrm{TRM}\left[\mathrm{H}_{\mathrm{c}}\right], \mathrm{ARM}_{1}\right.$ $\left[\mathrm{H}_{\mathrm{c}}\right]$, and $\mathrm{ARM}_{2}\left[\mathrm{H}_{\mathrm{c}}\right]$ ) should be calculated in the same manner.

[4] Contrary to these requirements, Pan et al. [2002] use nonsubtracted ARMs. Therefore the paleointensity results obtained by Rolph's correction are wrongly calculated. This is particularly important for set $\mathrm{C}$, because a significant fraction of the TRMs in this set survived after the maximum AF cleaning step [Pan et al., 2002, Figure 2]. On the other hand, the paleointensities of the samples from sets A and B were not significantly affected because of the negligible amount of remanence after the maximum AF cleaning step.

[5] Therefore the conclusion derived from set $\mathrm{C}$ by Pan et al. [2002] should be reconsidered after proper calculations. An example is shown for sample C20 (Figure 1): (1) the apparent magnitudes of NRM, TRM, $\mathrm{ARM}_{1}$ and $\mathrm{ARM}_{2}$ for various $\mathrm{AF}$ steps $\left(\mathrm{NRM}^{\prime}\left[\mathrm{H}_{\mathrm{c}}\right], \mathrm{TRM}^{\prime}\left[\mathrm{H}_{\mathrm{c}}\right], \mathrm{ARM}_{1}^{\prime}\left[\mathrm{H}_{\mathrm{c}}\right]\right.$, and $\left.\mathrm{ARM}_{2}^{\prime}\left[\mathrm{H}_{\mathrm{c}}\right]\right)$ were digitized from the original figure [Pan et al., 2002, Figure 2], and then the true remanences $\left(\mathrm{NRM}\left[\mathrm{H}_{\mathrm{c}}\right], \mathrm{TRM}\left[\mathrm{H}_{\mathrm{c}}\right], \mathrm{ARM}_{1}\left[\mathrm{H}_{\mathrm{c}}\right]\right.$, and $\left.\mathrm{ARM}_{2}\left[\mathrm{H}_{\mathrm{c}}\right]\right)$ were calculated by scalar subtraction of the apparent remanence at the maximum AF step $\left(\mathrm{NRM}^{\prime}[120 \mathrm{mT}], \mathrm{TRM}^{\prime}[120 \mathrm{mT}]\right.$, $\mathrm{ARM}_{1}^{\prime}[120 \mathrm{mT}]$, and $\left.\mathrm{ARM}_{2}^{\prime}[120 \mathrm{mT}]\right)$ from that at the corresponding AF step $\left(\mathrm{NRM}^{\prime}\left[\mathrm{H}_{\mathrm{c}}\right], \mathrm{TRM}^{\prime}\left[\mathrm{H}_{\mathrm{c}}\right], \mathrm{ARM}_{1}^{\prime}\left[\mathrm{H}_{\mathrm{c}}\right]\right.$, ], and $\left.\mathrm{ARM}_{2}^{\prime}\left[\mathrm{H}_{\mathrm{c}}\right]\right)$; (2) $\mathrm{TRM}^{*}\left[\mathrm{H}_{\mathrm{c}}\right]$ was then calculated by $\mathrm{TRM}\left[\mathrm{H}_{\mathrm{c}}\right] \times\left(\mathrm{ARM}_{1}\left[\mathrm{H}_{\mathrm{c}}\right] / \mathrm{ARM}_{2}\left[\mathrm{H}_{\mathrm{c}}\right]\right)$. We did not perform vector subtraction because the remanences were presented not in vector but in scalar form in the original figure. The resultant diagram (Figure 1) does not have good linearity. It is quite different from the original figure [Figure 2; Pan et al., 2002], and I consider this difference to be mainly due to the erroneous correction.

[6] This view is also supported by the relations in NRM$\mathrm{ARM}_{1}$ and TRM-ARM ${ }_{2}$. Since Rolph's correction always needs linear segments in the TRM*-NRM diagram [Rolph and Shaw, 1985], ratios of NRM/TRM* should be constant for different coercivities, that is,

$$
\frac{\mathrm{NRM}\left[\mathrm{H}_{\mathrm{c}}\right]}{\mathrm{TRM}^{*}\left[\mathrm{H}_{\mathrm{c}}\right]}=\frac{\mathrm{ARM}_{2}\left[\mathrm{H}_{\mathrm{c}}\right] / \mathrm{TRM}\left[\mathrm{H}_{\mathrm{c}}\right]}{\mathrm{ARM}_{1}\left[\mathrm{H}_{\mathrm{c}}\right] / \mathrm{NRM}\left[\mathrm{H}_{\mathrm{c}}\right]}=\text { const. }
$$

This relationship indicates that $\mathrm{TRM}^{-\mathrm{ARM}_{2}}$ diagrams should be linear when the NRM-ARM 1 plots are linear. This necessary condition is, however, not achieved in the result of sample C20 of Pan et al. [2002]: A linear relationship is recognized only between NRM and $\mathrm{ARM}_{1}$, and is not observed between TRM and $\mathrm{ARM}_{2}$ [Pan et al., 2002, Figure 5]. Since the NRM-TRM* plot has excellent linearity [Pan et al., 2002, Figure 2], there is a contradiction. This contradiction can be explained by the erroneous correction. A similar erroneous correction was probably made in the case of sample $\mathrm{C} 03$ of Pan et al. [2002] because a similar contradiction is seen. Hence it may be said that Rolph's correction for set $\mathrm{C}$ samples in most cases gives neither correct nor incorrect paleointensities because of their nonlinear NRM-TRM* diagrams. These results can simply be discarded without reference to any rock magnetic information such as the "P value" [Pan et al., 2002, section 4.2]. Accordingly, Rolph's correction might not yield incorrect paleointensities for strongly
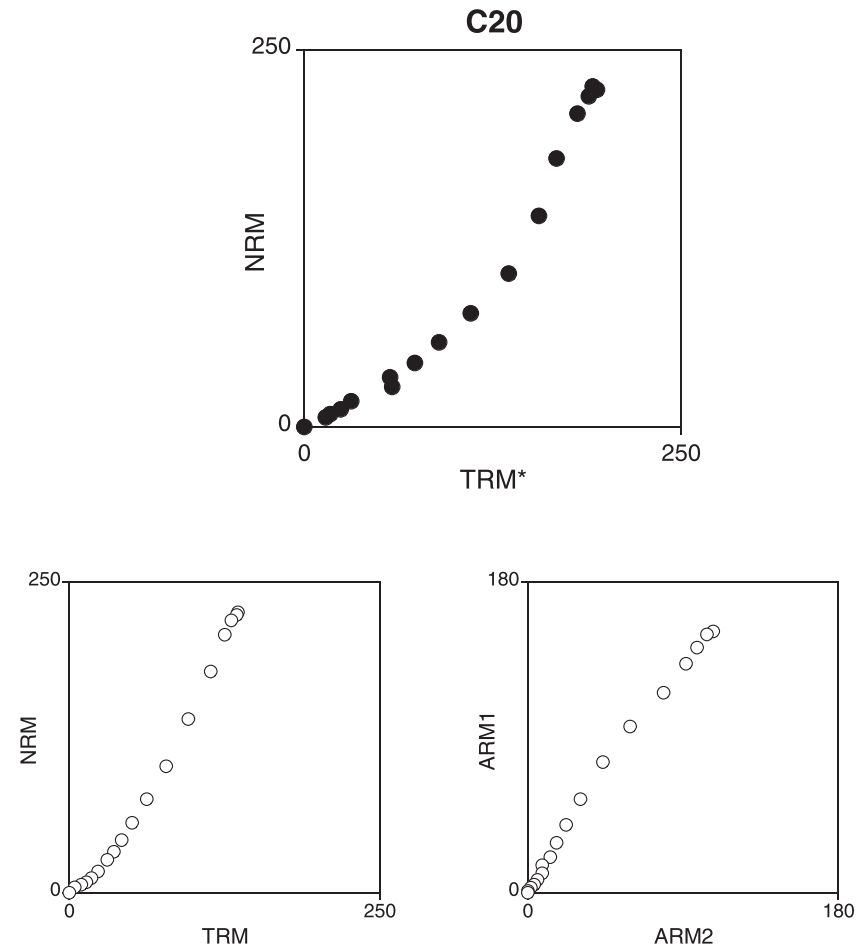

Figure 1. Example of the recalculated paleointensity plots for sample C20. The resultant NRM-TRM* diagram does not have good linearity and is quite different from the original figure [Pan et al., 2002, Figure 2].

altered samples. This conclusion is different from that of Pan et al. [2002]. They conclude that set C samples sometime invalidated Rolph's correction, giving wrong paleointensities. They also conclude that monitoring rock magnetic properties was therefore very important to avoid incorrect paleointensity estimates.

[7] A final comment is that the definition of the " $P$ value" [Pan et al., 2002, section 4.2] seems invalid when considered in terms of the principles of ARM. Pan et al. [2002] defined the " $P$ value" as the percentage difference in residual magnetization between $\mathrm{ARM}_{2}$ and $\mathrm{ARM}_{1}$ divided by $\mathrm{ARM}_{1}$. They gave those ARMs in a maximum peak AF field of $150 \mathrm{mT}$ with an associated direct field of $100 \mu \mathrm{T}$. Since these remanences were subjected to stepwise AF demagnetization up to almost the same peak field, the ARMs are completely demagnetized in principle, so no "residual" ARMs should be observed. Therefore the observed remanences are not residual ARMs but remaining NRM or TRM. I think that the " $P$ value" should be defined as the percentage difference in residual magnetization between TRM and NRM divided by NRM, that is (residual $\mathrm{TRM}$ - residual NRM)/(initial NRM) $\times 100$.

[8] Acknowledgments. I thank Nobutatsu Mochizuki, Tokyo Institute of Technology, for several valuable discussions. I also appreciate the constructive comments of Toshitsugu Yamazaki, Geological Survey of Japan, AIST. I acknowledge Carlo Laj for his comments regarding the English.

\section{References}

Goguitchaichvili, A., M. Prevot, and P. Camps, No evidence for strong fields during the R3-N3 Icelandic geomagnetic reversal, Earth Planet. Sci. Lett., 167, 15-34, 1999. 
Kono, M., Reliability of paleointensity methods using alternating field demagnetization and anhysteretic remanence, Geophys. J. R. Astron. Soc., 54, 241-261, 1978.

Pan, Y., J. Shaw, R. Zhu, and M. J. Hill, Experimental reassessment of the Shaw paleointensity method using laboratory-induced thermal remanent magnetization, J. Geophys. Res., 107(B7), 2129, 10.1029/2001JB000620, 2002.

Rolph, T. C., and J. Shaw, A new method of paleofield magnitude correction for thermally altered samples and its application to Lower Carboniferous lavas, Geophys. J. Int., 80, 773-781, 1985.

Shaw, J., A new method of determining the magnitude of the paleomagnetic field: Application to five historic lavas and five archaeological samples, Geophys. J. R. Astron. Soc., 76, 637-651, 1974.
Tsunakawa, H., and J. Shaw, The Shaw method of paleointensity determinations and its application to recent volcanic rocks, Geophys. J. Int., 118, 781-787, 1994

Vlag, P., L. Alva-Valdivia, C. B. de Boer, S. Gonzalez, and J. UrrutiaFucugauchi, A rock-and paleomagnetic study of a Holocene lava flow in central Mexico, Phys. Earth Planet. Inter., 118, 259-272, 2000.

Y. Yamamoto, Institute for Marine Resources and Environment, Geological Survey of Japan, AIST, Tsukuba, Ibaraki 305-8567, Japan. (yuhji-yamamoto@aist.go.jp) 